Article

\title{
Preparation of Gellan Gum-Inorganic Composite Film and Its Metal Ion Accumulation Property
}

\author{
Masanori Yamada *(D) and Yoshihiro Kametani
}

Department of Chemistry, Faculty of Science, Okayama University of Science, Ridaicho, Kita-ku, Okayama 700-0005, Japan; kametani.ous@gmail.com

* Correspondence: myamada@chem.ous.ac.jp

check for updates

Citation: Yamada, M.; Kametani, Y. Preparation of Gellan Gum-Inorganic Composite Film and Its Metal Ion Accumulation Property. J. Compos. Sci. 2022, 6, 42. https://doi.org/ $10.3390 /$ jcs 6020042

Academic Editor: Konda Gokuldoss Prashanth

Received: 6 January 2022

Accepted: 23 January 2022

Published: 25 January 2022

Publisher's Note: MDPI stays neutral with regard to jurisdictional claims in published maps and institutional affiliations.

Copyright: (C) 2022 by the authors. Licensee MDPI, Basel, Switzerland. This article is an open access article distributed under the terms and conditions of the Creative Commons Attribution (CC BY) license (https:// creativecommons.org/licenses/by/ $4.0 /)$.

\begin{abstract}
Gellan gum is one of the water-soluble anionic polysaccharides produced by the bacteria Sphingomonas elodea. In this study, we prepared gellan gum-inorganic composite films by mixing the gellan gum and a silane coupling reagent-3-glycidoxypropyltrimethoxysilane (GPTMS). These gellan gum-GPTMS composite films were stable in an aqueous solution and showed a thermal stability. In addition, these composite films indicated a mechanical strength by the formation of the three-dimensional network of siloxane. We demonstrated the accumulation of metal ions from a metal ion-containing aqueous solution by the composite film. As a result, although the composite film indicated the accumulation of heavy and rare-earth metal ions, the light metal ions, such as $\mathrm{Mg}$ (II) and $\mathrm{Al}(\mathrm{III})$ ions, did not interact with the composite material. Therefore, the accumulative mechanism of metal ions using a composite film was evaluated by IR measurements. As a consequence, although the accumulation of heavy and rare-earth metal ions occurred at both the $-\mathrm{COO}^{-}$group and the $-\mathrm{OH}$ group in the gellan gum, the accumulation of light metal ions occurred only at the $-\mathrm{OH}$ group.
\end{abstract}

Keywords: environmentally benign; biopolymer; absorbent; composite; biomaterial

\section{Introduction}

Gellan gum is one of the water-soluble anionic polysaccharides produced by the bacteria Sphingomonas elodea. Generally, the repeating unit of the gellan gum is a tetrasaccharide, which consists of two D-glucose residues, the L-rhamnose residue and D-glucuronic acid residue $[1,2]$. Since the D-glucuronic acid possesses the $-\mathrm{COOH}$ group in its molecular structure, the gellan gum is dissolved in water by the repulsion force of the $-\mathrm{COO}^{-}$group. In addition, the $-\mathrm{COO}^{-}$group interacts with metal ions, such as calcium ions, and produces the hydrogel. These hydrogels of gellan gum have been used as a microbiological culture or a plant cell culture [3]. Furthermore, gellan gum is a low cost, safe for humans, and environmentally benign polymer. Therefore, gellan gum has been utilized as a gelling agent in eye drops, food, and cosmetics [4]. Recently, the biomedical applications of gellan gum have also been reported [5,6]. In the chemical field, gellan gum has been used for the ion-exchange and the accumulation of metal ions [7-9]. However, since gellan gum does not show a mechanical strength, gellan gum-containing material, as an absorbent of metal ions, cannot be used for a long time under practical conditions. Furthermore, since gellan gum is highly water soluble, it is difficult to use gellan gum in water without complexing. Therefore, the preparation of gellan gum-containing material with water-stability, thermal stability, and mechanical strength is important from a material science point of view. One of the strategies to solve these problems is using organic-inorganic composite materials [10-13], which are prepared by complexing an organic polymer with a silane coupling reagent.

Organic-inorganic composite materials [10-13] have attracted much attention as functional materials with a thermal stability, mechanical strength, and stabilization of unstable chemical compounds, etc. Since these organic-inorganic composite materials possess both the properties of organic and inorganic components, these materials indicate a 
flexibility and strength. In addition, the organic-inorganic composite materials are prepared by a soft process, such as sol-gel reaction using a silane coupling reagent, and can use various biopolymers, such as proteins, DNA, and polysaccharides, as an organic component [14-16]. These biopolymer-inorganic composite materials have been reported for use as an absorbent of harmful compounds [16], sensing materials [17], energy materials [18,19], biomaterials [20], etc. Therefore, composite film consisting of gellan gum and an inorganic component can be expected to be used as a novel environmental material.

In this study, we prepared water-insoluble gellan gum-inorganic composite films by mixing the gellan gum and a silane coupling reagent-3-glycidoxypropyltrimethoxysilane (GPTMS). The gellan gum in the composite material was encapsulated in the three-dimensional network of the siloxane. In addition, the gellan gum was immobilized on the network by the formation of covalent bonding due to the ring-opening reaction of the epoxy group. As a result, the composite film showed not only a water-stabilization, but also a thermal stability and mechanical strength. Furthermore, the composite film accumulated the heavy and rare-earth metal ions from a metal ion-containing aqueous solution. These accumulations of metal ions from an aqueous solution were due to the interaction with the $-\mathrm{COOH}$ group and $-\mathrm{OH}$ group in the gellan gum.

\section{Materials and Methods}

\subsection{Material}

Gellan gum and the silane coupling reagent, 3-glycidoxypropyltrimethoxysilane (GPTMS), were purchased from Fujifilm Wako Pure Chemical Industries, Ltd., Osaka, Japan and Shin-Etsu Chemical Co., Ltd., Tokyo, Japan, respectively. Scheme 1 shows the molecular structure of GPTMS. The copper(II) chloride dihydrate, zinc(II) chloride, nickel(II) chloride hexahydrate, scandium(III) chloride hexahydrate, yttrium(III) chloride hexahydrate, lanthanum(III) chloride heptahydrate, indium(III) chloride tetrahydrate, aluminium(III) chloride hexahydrate, magnesium(II) chloride hexahydrate, and calcium(II) chloride dehydrate were obtained from Fujifilm Wako Pure Chemical Industries Ltd. or Kanto Chemical Co., Inc., Tokyo, Japan. The standard solution of metal ion obtained from Fujifilm Wako Pure Chemical Industries. Xylenol orange (XO) and methylthymol blue (MTB) were purchased from Dojindo Co., Kumamoto, Japan and Fujifilm Wako Pure Chemical Industries Ltd., respectively. The strongly acidic ion-exchange resin, Amberlite IR120(H) was obtained from Supelco, Bellefonte, PA. Analytical grade solvents were used in all of the experiments described. Ultra-pure water (Merck KGaA, Darmstadt, Germany) was used in this experiment.

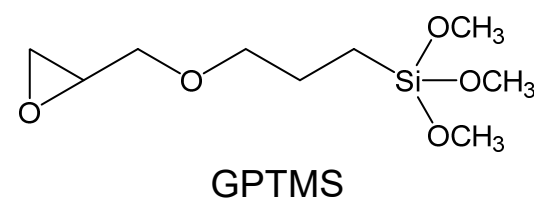

Scheme 1. The molecular structure of GPTMS.

\subsection{Preparation of Gellan Gum-GPTMS Composite Film}

The gellan gum-GPTMS composite film was prepared as follows: the gellan gum was dissolved in water. The aqueous gellan gum solution $(5 \mathrm{mg} / \mathrm{mL})$ was obtained by centrifugation. The GPTMS solution was applied as an aqueous gellan gum solution and this mixed solution of $100 \mu \mathrm{L}$ was cast onto a Teflon ${ }^{\circledR}$ plate and reacted at $90^{\circ} \mathrm{C}$ for $20 \mathrm{~min}$. These dried composite films were stripped from the Teflon ${ }^{\circledR}$ plate, washed by water, then stored in water. The mixing ratio ( $\mathrm{wt} \%$ ) of the gellan gum and GPTMS was determined by Equation (1)

$$
\mathrm{wt} \%=\frac{[\text { weight of GPTMS }]}{[\text { weight of gellan gum }]+[\text { weight of GPTMS }]} \times 100,
$$


where [weight of gellan gum] and [weight of GPTMS] of Equation (1) are the weights of the gellan gum and GPTMS in the mixed solution, respectively. The mixing ratio of the gellan gum and GPTMS varied from 0 to $50 \mathrm{wt} \%$.

The amount of $-\mathrm{COOH}$ in the gellan gum was evaluated as follows: the metal ions, such as sodium and potassium ions, in the gellan gum was changed to $\mathrm{H}^{+}$by an ion exchange column using a strongly acidic ion exchange resin. The ion exchange of the gellan gum was confirmed by a $\mathrm{pH}$ measurement. The resulting aqueous solution of the protonated gellan gum was freeze-dried for more than 2 days. The amount of $-\mathrm{COOH}$ in the gellan gum was estimated by neutralization titration and this value was $3.90 \times 10^{-4} \mathrm{~mol} \mathrm{~g}^{-1}$.

\subsection{Water Stability of Gellan Gum-GPTMS Composite Film}

The water stability of the gellan gum-GPTMS composite film was evaluated as follows: the weight of the dried gellan gum-GPTMS composite film was quantified by a precision balance and incubated in ultra-pure water $(5 \mathrm{~mL})$ for various times. The incubated composite films were dried at RT for more than $12 \mathrm{~h}$, then quantified by the precision balance once more. The water-stability of the composite film was evaluated from the weight difference before and after its immersion.

\subsection{Structural and Thermal Analyses of Gellan Gum-GPTMS Composite Film}

The infrared (IR) absorption spectra of the gellan gum-GPTMS composite film were characterized using an IR spectrophotometer FT/IR-4700 (JASCO Corporation, Tokyo, Japan) equipped with the diamond attenuated total reflection (ATR) prism. The IR spectrum was measured with a resolution of $4 \mathrm{~cm}^{-1}$. The thermal stability of the gellan gum composite film was analyzed by a thermogravimetric - differential thermal analysis (TG-DTA) (DTG-60, Shimadzu Corp., Kyoto, Japan). The TG-DTA measurement was carried out at the heating rate of $10^{\circ} \mathrm{C} \mathrm{min}^{-1}$ in flowing dry nitrogen. The sample weights of the TG-DTA measurements were normalized at $1 \mathrm{mg}$.

\subsection{Tensile Strength of Gellan Gum-GPTMS Composite Film}

The gellan gum-GPTMS composite film was cut into $5 \times 15 \mathrm{~mm}^{2}$ pieces. The thickness of the composite film was measured by a thickness gauge ID-C $\mathrm{X}$ series (Mitutoyo Corporation, Kanagawa, Japan). The thickness of the film was $20 \mu \mathrm{m}$. The tensile stress and strain was measured using a digital force gauge ZTA-50N (Imada Co., Ltd., Aichi, Japan) and test stand MX2-500N (Imada Co., Ltd.). The temperature and relative humidity during the tensile strength measurements were $20^{\circ} \mathrm{C}$ and $50 \pm 10 \%$, respectively [16]. The initial length of the composite film was $5 \mathrm{~mm}$ and the drawing speed was $10 \mathrm{~mm} \mathrm{~min}{ }^{-1}$. The tensile stress and strain values were expressed as an average of 10 measurements.

\subsection{Accumulation of Metal Ions by Gellan Gam-GPTMS Composite Film}

All the metal chlorides were separately dissolved in pure water. The concentrations of the aqueous metal ion solutions were $0-100 \mathrm{ppm}$. The accumulation of metal ions by the gellan gum-GPTMS composite film was demonstrated as follows: one gellan gumGPTMS composite film was added to each metal ion-containing aqueous solution, the solutions were stirred at RT for $6 \mathrm{~h}$, then the composite films were separated from the aqueous solutions. The accumulated amount of the metal ions was determined by the absorbance of the aqueous solutions in the absence or presence of the gellan-gum composite film. The concentrations of the aqueous metal ion solutions were estimated from the calibration curve with the metal indicator XO and MTB [21]. The accumulated amounts of the metal ions by the gellan gum-GPTMS composite film were expressed as an average of three measurements. 


\subsection{IR Measurements of Metal Ion-Accumulated Gellan Gum-GPTMS Composite Film}

The metal ion-accumulated gellan gum-GPTMS composite film was prepared as follows: the composite films were incubated in the metal ion-containing aqueous solutions $(10 \mathrm{~mL})$ with various concentrations for more than $24 \mathrm{~h}$. The obtained metal ionaccumulated composite films were washed using pure water $(10 \mathrm{~mL} \times 3$ times $)$ and dried at RT for more than $12 \mathrm{~h}$. These samples were analyzed by the ATR method using an IR spectrometer.

\section{Results and Discussion}

\subsection{Preparation of Gellan Gum-GPTMS Composite Film}

Figure 1a shows a photograph of the dried gellan gum- $5 \mathrm{wt} \%$ GPTMS composite film. This composite film was a transparent and flexible material. The thickness of the composite film in Figure 1a was approximately $20 \mu \mathrm{m}$. The thickness of the composite film could be controlled by the amount of casting onto the plate.

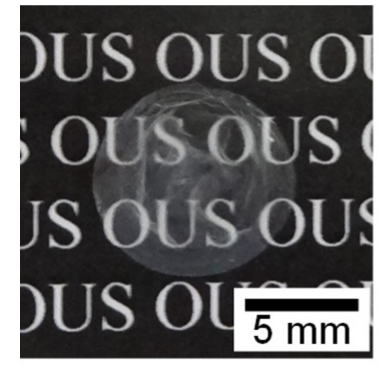

(a)

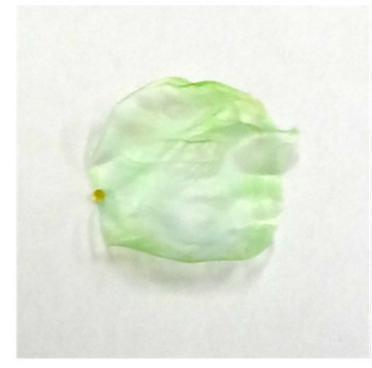

(b)

Figure 1. Photograph of gellan gum-5 wt\% GPTMS composite film. (a) Dried composite film. (b) Dried Cu(II) ion-accumulated composite film.

We evaluated the water-stability of the gellan gum-GPTMS composite material. Figure 2

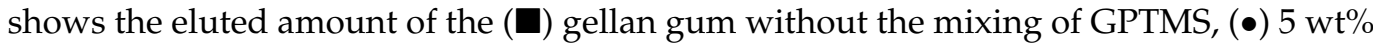
GPTMS, (○) $10 \mathrm{wt} \%$ GPTMS, (ム) $30 \mathrm{wt} \%$ GPTMS, and $(\triangle) 50 \mathrm{wt} \%$ GPTMS composite films. When the gellan gum film without the GPTMS mixing was immersed in water, the film immediately dissolved and reached a constant value of approximately $60 \%$ at $1 \mathrm{~h}$. The composite film with the addition of GPTMS showed a decrease in the eluted amount. The eluted amount of the gellan gum-5 wt \% GPTMS was approximately 20\% after $24 \mathrm{~h}$ and these eluted amounts did not depend on the mixing ratio of the GPTMS. Additionally, although the composite films were incubated in water for more than 1 week, these films did not dissolve. Therefore, the gellan gum-GPTMS composite films were stored in ultra-pure water for more than $1 \mathrm{~h}$ to remove the water-soluble components, then used in the experiments. Particularly, in the accumulative measurements of metal ions by the composite film, we used the gellan gum $-5 \mathrm{wt} \%$ GPTMS composite film, which is the lowest mixing ratio of the inorganic components.

\subsection{Molecular Structure of Gellan Gum-GPTMS Composite Film}

The gellan gum-GPTMS composite film showed a stability in the aqueous solution. Generally, the epoxy group reacts with the $-\mathrm{OH}$ group and produces ether bonding and a secondary alcohol by the ring-opening reaction [22]. Since the gellan gum and GPTMS molecule possesses a lot of $-\mathrm{OH}$ groups and an epoxy group in its structure, respectively, a similar reaction might occur in the composite film. In addition, the $\mathrm{Si}-\mathrm{OCH}_{3}$ group in the GPTMS molecule produces the silanol group by hydrolysis, then the silanol group is condensed to siloxanes by dehydration $[13,14]$. The polymerization with the condensation of the silanol group forms the three-dimensional network of siloxanes in the composite film. Therefore, we evaluated the molecular structure of a gellan gum-GPTMS composite film using IR spectrometry. 


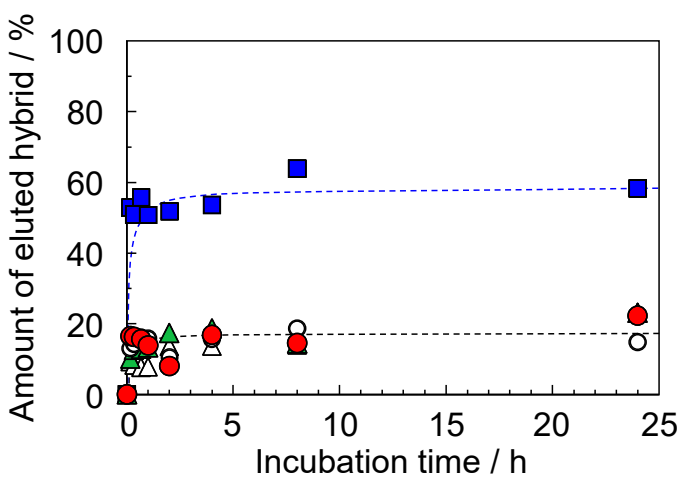

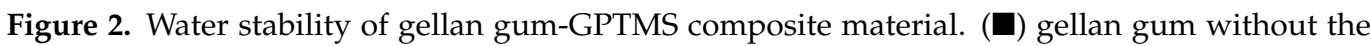
mixing of GPTMS, $(\bullet)$ gellan gum-5 wt $\%$ GPTMS, $(\bigcirc)$ gellan gum-10 wt $\%$ GPTMS, $(\boldsymbol{\Delta})$ gellan gum-30 wt $\%$ GPTMS, and $(\triangle)$ gellan gum-50 wt $\%$ GPTMS composite films. Each value represents the mean of three separation determinations.

Figure 3 shows the IR spectra of (a) gellan gum without the mixing of GPTMS, (b) gellan gum $-5 \mathrm{wt} \%$ GPTMS, (c) gellan gum $-10 \mathrm{wt} \%$ GPTMS, (d) gellan gum- $30 \mathrm{wt} \%$ GPTMS, (e) gellan gum-50 wt\% GPTMS, and (f) GPTMS without mixing of the gellan gum. The GPTMS without any mixing used a sample that was condensed by heat treatment. When the GPTMS molecules were added to the gellan gum, the absorption band at around $1000 \mathrm{~cm}^{-1}$, attributed to the stretching vibration of $\mathrm{Si}-\mathrm{O}-\mathrm{Si}$, increased and broadened. These results indicated the formation of the siloxane network in the composite film by the addition of the GPTMS molecule. Similar reactions have been reported for a biopolymerinorganic composite material using a silane coupling reagent [15]. The absorption band at ca. $1600 \mathrm{~cm}^{-1}$, indicating the stretching vibration of the $-\mathrm{COO}^{-}$group $[19,23,24]$, did not show a shift by the addition of GPTMS molecule. These results indicated that the addition of the GPTMS did not affect the $-\mathrm{COO}^{-}$group, which can interact with various metal ions. On the other hand, when the gellan gum was added to the GPTMS, the absorption bands at $911 \mathrm{~cm}^{-1}$, the stretching vibration of $\mathrm{C}-\mathrm{O}$ in the epoxy group $[25,26]$, relatively decreased. Additionally, the absorption bands at $820 \mathrm{~cm}^{-1}$, the stretching vibration of $\mathrm{C}-\mathrm{O}-\mathrm{C}$ with the distortion in the epoxy group $[25,26]$, disappeared. Furthermore, the absorption band at $1067 \mathrm{~cm}^{-1}$, related to the stretching vibration of $\mathrm{C}-\mathrm{O}-\mathrm{C}$ without the distortion in ether $[23,25,26]$, increased with the gellan gum mixing. As a result, in the gellan gum-GPTMS composite film, the epoxy group in the GPTMS reacted with the $-\mathrm{OH}$ group in the gellan gum and produced the ether bonding by the ring-opening reaction. These results suggested that the gellan gum was encapsulated into the three-dimensional network of the siloxane in the composite film. Furthermore, the gellan gum was immobilized on the network by covalent bonding, which was produced by the ring-opening reaction between the $-\mathrm{OH}$ group and the epoxy group. Therefore, the elution of the gellan gum-GPTMS composite film into water decreased and the composite film provided the water insolubility.

\subsection{Thermal Stability of Gellan Gum-GPTMS Composite Film}

Figure $4 \mathrm{~A}, \mathrm{~B}$, respectively, show the thermogravimetric (TG) analysis and differential thermal analysis (DTA) curves of (a) gellan gum without the mixing of GPTMS, (b) gellan gum- $5 \mathrm{wt} \%$ GPTMS composite, (c) gellan gum-10 wt $\%$ GPTMS composite, and (d) GPTMS without the mixing of the gellan gum at a heating rate of $10^{\circ} \mathrm{C} \mathrm{min}^{-1}$ up to $300^{\circ} \mathrm{C}$ in flowing dry nitrogen. The GPTMS without the mixing was used as a sample, which was condensed by the heat treatment. The gellan gum without the GPTMS mixing and the composite film showed that the TG weight loss of approximately $10 \%$ related to the evaporation of water components from the material at $<100^{\circ} \mathrm{C}$. Additionally, the gellan gum indicated an exothermic peak at $237.6^{\circ} \mathrm{C}$. This peak is due to the thermal decomposition of the gellan gum and the gellan gum showed high TG weight loss at temperatures greater than $250^{\circ} \mathrm{C}$. 
A similar exothermic peak and TG weight loss at around $250{ }^{\circ} \mathrm{C}$ were also obtained for the gellan gum-GPTMS composite film (see line (b) and (c) in Figure 4). These exothermic peaks decreased and broadened with the GPTMS mixing ratio. These results suggested that the gellan gum was thermally stabilized by the mixing of the inorganic component, such as GPTMS. This is caused by the encapsulation of the gellan gum into the three-dimensional network of siloxane and the formation of the covalent bonding between the $-\mathrm{OH}$ group in the gellan gum and the epoxy group in the GPTMS. Therefore, the gellan gum thermally stabilized with the addition of GPTMS. These phenomena, such as the thermal stabilization by the encapsulation of the biopolymer into the inorganic network, have been reported for a biopolymer-inorganic composite material [16,19].

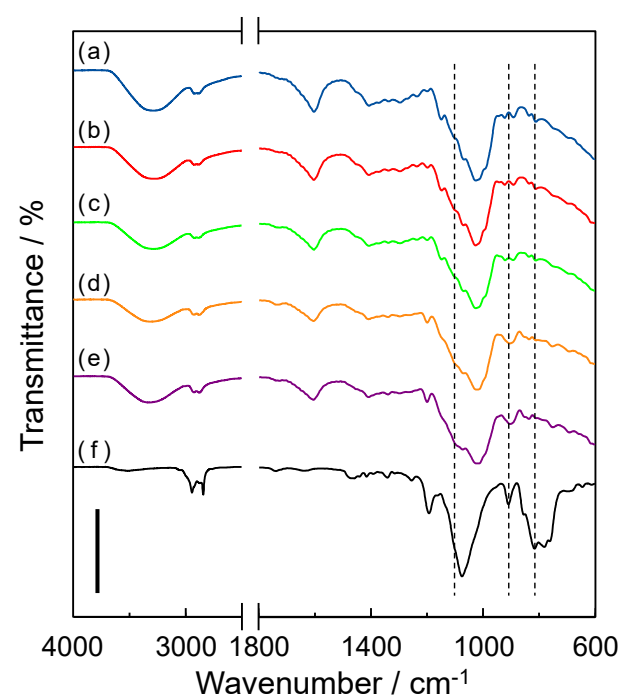

Figure 3. IR spectra of (a) gellan gum without the mixing of GPTMS, (b) gellan gum- $5 \mathrm{wt} \%$ GPTMS, (c) gellan gum- $10 \mathrm{wt} \%$ GPTMS, (d) gellan gum- $30 \mathrm{wt} \%$ GPTMS, (e) gellan gum- $50 \mathrm{wt} \%$ GPTMS, and (f) GPTMS without the mixing of gellan gum. The GPTMS without any mixing was used as a sample that was condensed by heat treatment. The IR spectrum was measured at the resolution of $4 \mathrm{~cm}^{-1}$. The scale bar indicates the transmittance of 50\%. Triplicate experiments gave similar results.

(A)

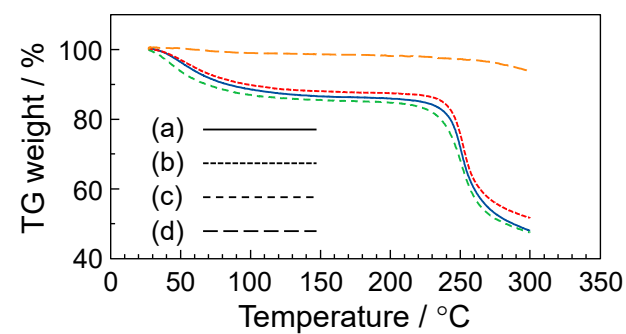

(B)

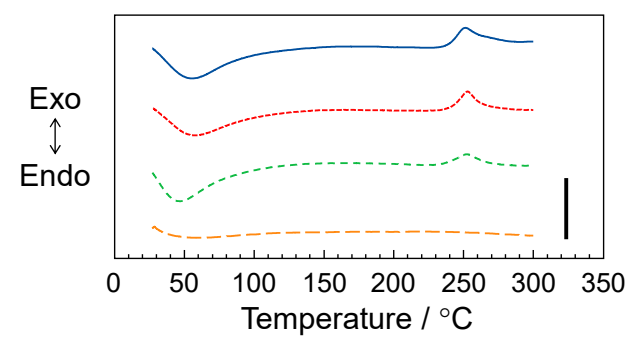

Figure 4. TG (A) and DTA (B) curves of gellan gum-GPTMS composite material at the heating rate of $10{ }^{\circ} \mathrm{C} \mathrm{min}{ }^{-1}$ to $300{ }^{\circ} \mathrm{C}$ in flowing dry nitrogen. (a) Gellan gum without the mixing of GPTMS, (b) gellan gum- $5 \mathrm{wt} \%$ GPTMS composite, (c) gellan gum-10 wt\% GPTMS composite, and (d) GPTMS without the mixing of gellan gum. Scale bar in Figure 4B indicates $20 \mu \mathrm{V} \mathrm{mg}^{-1}$. Triplicate experiments gave similar results. 


\subsection{Mechanical Strength of Gellan Gum-GPTMS Composite Film}

We measured the mechanical strength of the gellan gum-GPTMS composite film. Curves (a) and (b) in Figure 5 show the stress-strain curves of the gellan gum without the mixing of GPTMS and the gellan gum $-5 \mathrm{wt} \%$ GPTMS composite films, respectively. The tensile stress and strain values are expressed as an average of 10 measurements. When the stress was loaded on the gellan gum film without the mixing of GPTMS, the film broke at approximately $35 \mathrm{MPa}$ (see curve (a) in Figure 5). The elongation at the break point was approximately $3 \%$ and this film showed a brittle property. Next, we measured the gellan gum $-5 \mathrm{wt} \%$ GPTMS composite film. The composite film broke at approximately $55 \mathrm{MPa}$ and this breaking strength of the composite film was 1.8 times greater than that of the gellan gum film (see curve (b) in Figure 5). This phenomenon is due to the composite effect from the mixing of the inorganic component, such as GPTMS, with the gellan gum. A similar effect, such as the increase in the mechanical strength by the addition of inorganic components, was obtained for the double-stranded DNAbis(trimethoxysilylpropyl)amine hybrid material [16]. In the gellan gum-GPTMS composite film, the increase in the mechanical strength by the addition of inorganic components effectively occurred at a lower mixing ratio, i.e., $5 \mathrm{wt} \%$, than for the other composite materials [16,27]. This is due to not only the encapsulation of the gellan gum into the three-dimensional network of siloxane, but also the immobilization of the gellan gum by the covalent bonding via the ring-opening reaction of the epoxy group in the GPTMS. On the other hand, the elongation at the break point of the composite film was approximately $3.5 \%$ and this strain value was almost the same as that of the gellan gum without the mixing of GPTMS. Therefore, the composite film was also a brittle material.

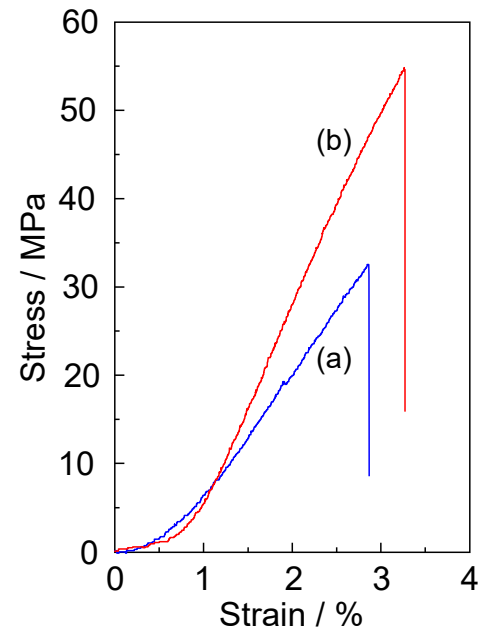

Figure 5. Stress-strain curves of (a) gellan gum without the mixing of GPTMS and (b) gellan gum $-5 \mathrm{wt} \%$ GPTMS composite films. These measurements were done at $20{ }^{\circ} \mathrm{C}$ under $50 \pm 10 \%$ relative humidity conditions. The initial length of the membrane was $5 \mathrm{~mm}$, and the separation rate was $10 \mathrm{~mm} \mathrm{~min}^{-1}$.

\subsection{Accumulation of Metal Ions by the Gellan Gum-GPTMS Composite Film}

The gellan gum possesses a carboxylate group in its structure. The amount of $-\mathrm{COOH}$ in the gellan gum was determined by neutralization titration and this value was $3.90 \times 10^{-4} \mathrm{~mol} \mathrm{~g}^{-1}$. It has been reported that the carboxylate group interacts with various metal ions [7-9,27]. Therefore, the water-insoluble gellan gum-GPTMS composite film is expected to accumulate various metal ions from an aqueous solution. We demonstrated the immersion of the gellan gum $-5 \mathrm{wt} \%$ GPTMS composite film into the $\mathrm{Cu}$ (II) ion-containing aqueous solution. When the gellan gum-GPTMS composite film was incubated in a $\mathrm{Cu}$ (II) ion-containing aqueous solution for $24 \mathrm{~h}$, the composite film turned blue due to the accumulation of the $\mathrm{Cu}$ (II) ions. Figure $1 \mathrm{~b}$ shows a photograph of the dried $\mathrm{Cu}(\mathrm{II})$ 
ion-accumulated composite film. The color of the dried gellan gum-GPTMS composite film changed from transparent to blue. These results suggested that the gellan gum-GPTMS composite film can accumulate metal ions from a metal ion-containing aqueous solution.

We next evaluated the accumulative time of the metal ions. The gellan gum-GPTMS composite film was immersed in a $\mathrm{Cu}$ (II) ion-containing aqueous solution and measured the absorbance of an aqueous solution with the metal indicator $\mathrm{XO}$ at various time intervals. When the composite film was incubated in a $\mathrm{Cu}$ (II) ion-containing aqueous solution, the accumulated amount of $\mathrm{Cu}$ (II) ions increased with the incubation time and reached a constant value at $6 \mathrm{~h}$ (data not shown). A similar accumulative behavior, such as reaching a constant value at $6 \mathrm{~h}$, was also obtained for $\mathrm{Al}(\mathrm{III})$ ions. Therefore, we demonstrated the accumulation of metal ions after the incubation time of $6 \mathrm{~h}$.

Figure $6(\bullet),(\boldsymbol{\square})$, and $(\boldsymbol{\Lambda})$ show the accumulative amounts of $\mathrm{Ni}(\mathrm{II}), \mathrm{Y}(\mathrm{III})$, and $\mathrm{Mg}$ (II) ions, respectively, at various concentrations. The accumulated amount of $\mathrm{Ni}$ (II) ions increased with the initial concentration and reached a constant value at approximately $2.7 \mu \mathrm{mol}$. Similar accumulative behaviors were also obtained for the $\mathrm{Y}$ (III) and $\mathrm{Mg}$ (II) ions. The constant values of the $\mathrm{Y}(\mathrm{III})$ and $\mathrm{Mg}$ (II) ions were $1.5 \mu \mathrm{mol}$ and $0.5 \mu \mathrm{mol}$, respectively. Therefore, we defined the constant value as the maximum-accumulated amount of the metal ions by the gellan gum-GPTMS composite film. Table 1 shows the maximum-accumulated amount of the various metal ions. In addition we calculated the $N$ value, which is the number of carboxylate groups per metal ion using the maximum-accumulated amount. As a result, the maximum-accumulated amount of the metal ions could be divided into three groups, such as groups A-C. The maximum-accumulated amount of group A, such as the $\mathrm{Ni}(\mathrm{II})$ ion, was the highest value of these metal ions and this value was $2.7 \mu \mathrm{mol}$. In addition, the $N$ value of the $\mathrm{Ni}(\mathrm{II})$ ion was 3.4 and one $\mathrm{Ni}$ (II) ion was surrounded by $3.4-\mathrm{COOH}$ groups. The In(III), $\mathrm{La}(\mathrm{III}), \mathrm{Zn}(\mathrm{II}), \mathrm{Cu}(\mathrm{II}), \mathrm{Y}(\mathrm{III})$, and $\mathrm{Ca}(\mathrm{II})$ ions were classified as group B. The maximum-accumulated amounts in group B were 1.5-1.8 $\mu \mathrm{mol}$ and the $N$ values were approximately 6 . The $\mathrm{Sc}(\mathrm{III}), \mathrm{Al}(\mathrm{III})$, and $\mathrm{Mg}(\mathrm{II})$ ions were classified as group C. The maximum-accumulated amounts were $0.5-0.9 \mu \mathrm{mol}$ and the $N$ values were 10-19. These results suggested that the gellan gum-GPTMS composite film can effectively accumulate $\mathrm{Ni}(\mathrm{II})$ ions in group $\mathrm{A}$. In addition, the composite film can hardly accumulate $\mathrm{Mg}$ (II) ions in group C and the accumulated amount of the $\mathrm{Mg}$ (II) ions was less than one-fifth that of the $\mathrm{Ni}(\mathrm{II})$ ions. Therefore, the accumulative site of the metal ions in the gellan gum-GPTMS composite film was evaluated based on the IR measurements.

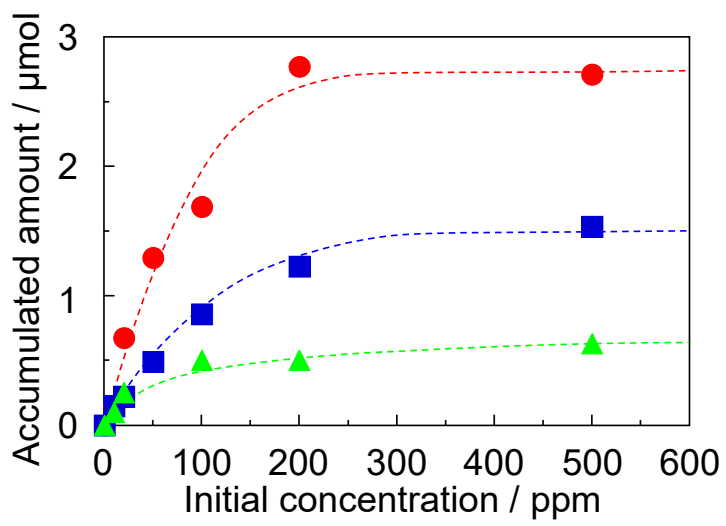

Figure 6. Accumulation of metal ions by gellan gum- $5 \mathrm{wt} \%$ GPTMS composite material for various

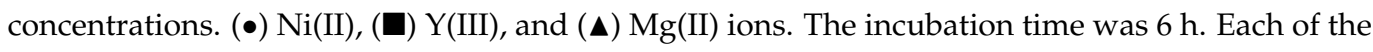
values represent the mean of three separate determinations.

On the other hand, the accumulation of metal ion by the gellan gum gel beads has been reported [28]. In this research, the accumulated amounts of $\mathrm{Ni}(\mathrm{II}), \mathrm{Zn}$ (II), and $\mathrm{Cu}$ (II) are $0.72 \mathrm{mmol} \mathrm{g}^{-1}, 0.71 \mathrm{mmol} \mathrm{g}^{-1}$, and $0.75 \mathrm{mmol} \mathrm{g}^{-1}$, respectively. In our research, the accumulated amounts of $\mathrm{Ni}(\mathrm{II}), \mathrm{Cu}(\mathrm{II})$, and $\mathrm{Zn}(\mathrm{II})$ were $0.48 \mathrm{mmol} \mathrm{g}^{-1}, 0.28 \mathrm{mmol} \mathrm{g}^{-1}$, 
and $0.26 \mathrm{mmol} \mathrm{g}^{-1}$, respectively. The accumulated amount of metal ion by the gellan gum-GPTMS composite material was lower than that by the gellan gum gel beads. This is due to the surface area. In our research, since the gellan gum-GPTMS composite material is in the form of a film, as it has a lower surface area than the gellan gum gel beads.

Table 1. The maximum-accumulated amount of various metal ions, the $N$ values, and classification of the metal ions.

\begin{tabular}{cccc}
\hline Metal Ions & Accumulated Amounts/ $\mathbf{m m o l}$ & $\boldsymbol{N}$ Values & Group \\
\hline $\mathrm{Ni}(\mathrm{II})$ & 2.7 & 3.4 & $\mathrm{~A}$ \\
$\mathrm{In}(\mathrm{II})$ & 1.8 & 5.1 & $\mathrm{~B}$ \\
$\mathrm{La}(\mathrm{III})$ & 1.6 & 5.8 & $\mathrm{~B}$ \\
$\mathrm{Zn}(\mathrm{II})$ & 1.6 & 5.8 & $\mathrm{~B}$ \\
$\mathrm{Cu}(\mathrm{II})$ & 1.5 & 6.2 & $\mathrm{~B}$ \\
$\mathrm{Y}(\mathrm{III})$ & 1.5 & 6.2 & $\mathrm{~B}$ \\
$\mathrm{Ca}(\mathrm{II})$ & 1.5 & 6.2 & $\mathrm{~B}$ \\
$\mathrm{Sc}(\mathrm{III})$ & 0.9 & 10.3 & $\mathrm{C}$ \\
$\mathrm{Al}(\mathrm{III})$ & 0.8 & 11.6 & $\mathrm{C}$ \\
$\mathrm{Mg}(\mathrm{II})$ & 0.5 & 18.5 & $\mathrm{C}$ \\
\hline
\end{tabular}

\subsection{IR Measurements of the Metal Ion-Accumulated Gellan Gum-GPTMS Composite Film}

In this measurement, the $\mathrm{Ni}(\mathrm{II}), \mathrm{Y}(\mathrm{III})$, and $\mathrm{Mg}(\mathrm{II})$ ions were used as the representative metal ions of group A, group B, and group C, respectively. The gellan gum-GPTMS composite films were incubated in a metal ion-containing aqueous solution of various concentrations for more than $24 \mathrm{~h}$. These dried samples were measured using an IR spectrophotometer equipped with the ATR prism. Figure 7A-C show the IR spectra of the Ni(II) ion-accumulated, Y(III) ion-accumulated, and $\mathrm{Mg}$ (II) ion-accumulated composite films, respectively. (a)-(d) in Figure 7 show the IR spectra of the prepared samples at the metal ion concentrations of $0 \mathrm{ppm}$ (gellan gum-GPTMS composite films without the accumulation of any metal ions), 500 ppm, 1000 ppm, and 2000 ppm, respectively. The gellan gun-GPTMS composite film without the accumulation of any metal ions showed an absorption band at $1602 \mathrm{~cm}^{-1}$, related to the symmetric stretching vibration of $-\mathrm{COO}^{-}[19,23,24,27]$. When the composite films were incubated in the $\mathrm{Ni}$ (II) ion- or Y(III) ion-containing aqueous solutions, which were classified in group A or group B, respectively, the absorption band shifted to a lower wavenumber, $10-15 \mathrm{~cm}^{-1}$, due to the accumulation of the metal ions. Additionally, these shifted values increased with the concentration of the metal ions (see spectra (a)-(d) in Figure 7A,B). These phenomena have been reported for the accumulation of metal ions by acidic polysaccharides [27]. On the other hand, when the composite film was incubated in the $\mathrm{Mg}(\mathrm{II})$ ion-containing aqueous solution, which was classified in group $\mathrm{C}$ and indicated a low binding affinity to the composite film, the IR spectra did not show any shift in the absorption band at $1602 \mathrm{~cm}^{-1}$. These results suggested that the metal ions mainly interacted with the $-\mathrm{COO}^{-}$group in the gellan gum by an electrostatic interaction.

Figure 8 shows the IR spectra of (a) gellan gum-5 wt\% GPTMS composite material, (b) $\mathrm{Ni}$ (II) ion-accumulated, (c) Y(III) ion-accumulated, and (d) $\mathrm{Mg}$ (II) ion-accumulated composite films at $2500-4000 \mathrm{~cm}^{-1}$. The concentration of the metal ions was $2000 \mathrm{ppm}$. The gellan gum-5 wt $\%$ GPTMS composite film showed an absorption band at $3290 \mathrm{~cm}^{-1}$, related to the stretching vibration of $\mathrm{O}-\mathrm{H}$ [23]. This absorption band was shifted to $3242 \mathrm{~cm}^{-1}, 3252 \mathrm{~cm}^{-1}$, and $3252 \mathrm{~cm}^{-1}$ by the accumulation of the $\mathrm{Ni}$ (II), Y(III), and $\mathrm{Mg}$ (II) ions, respectively. In particular, the $\mathrm{Ni}$ (II) ion-accumulated composite film showed the greatest shift in these samples. These results suggested that the metal ions interact with not only the $-\mathrm{COO}^{-}$group but also the $-\mathrm{OH}$ group in the gellan gum. Therefore, the accumulation of the heavy and rare-earth metal ions occurred at both the $-\mathrm{COO}^{-}$group and the $-\mathrm{OH}$ group. In contrast, the accumulation of $\mathrm{Mg}$ (II) ions occurred only at the $-\mathrm{OH}$ group. 
(A)

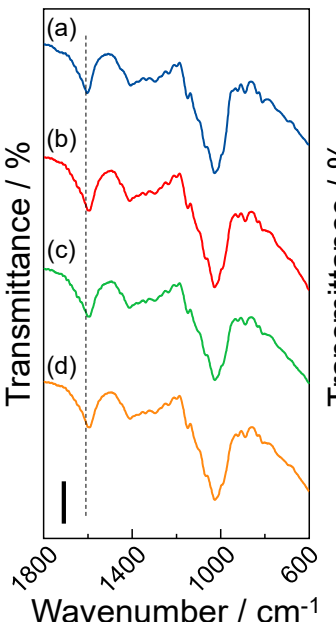

Wavenumber $/ \mathrm{cm}^{-1}$
(B)

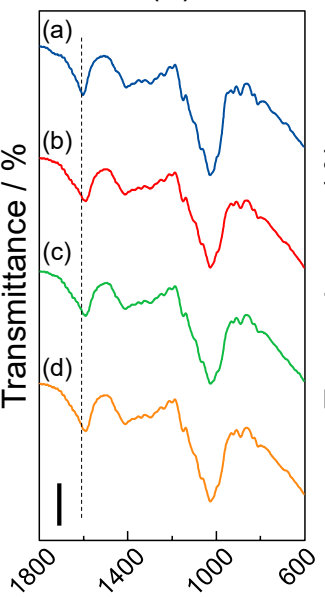

Wavenumber $/ \mathrm{cm}^{-1}$
(C)

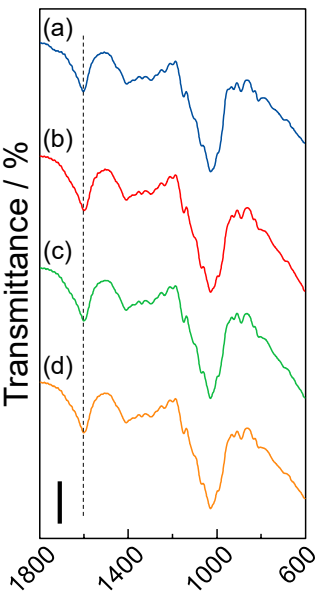

Wavenumber $/ \mathrm{cm}^{-1}$

Figure 7. IR spectra of (A) $\mathrm{Ni}$ (II) ion-accumulated, (B) Y(III) ion-accumulated, and (C) Mg(II) ionaccumulated gellan gum $-5 \mathrm{wt} \%$ GPTMS composite film. The concentrations of the metal ions were (a) 0 ppm (non-accumulation of metal ions), (b) $500 \mathrm{ppm}$, (c) $1000 \mathrm{ppm}$, and (d) $2000 \mathrm{ppm}$. The dashed line showed the absorption band at $1602 \mathrm{~cm}^{-1}$ related to the symmetric stretching vibration of $-\mathrm{COO}^{-}$. The IR spectrum was measured at the resolution of $4 \mathrm{~cm}^{-1}$. Each scale bar in Figure 7 indicates the transmittance of $20 \%$. Triplicate experiments gave similar results.

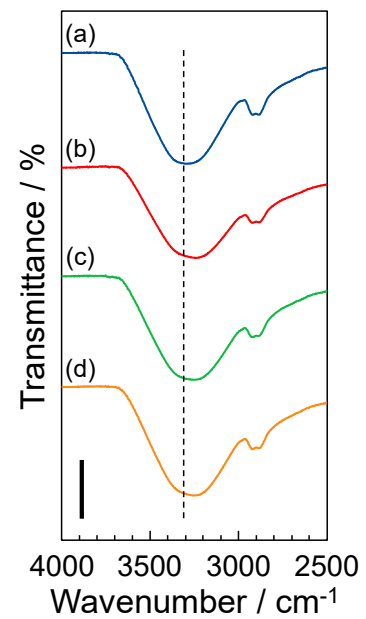

Figure 8. IR spectra of (a) gellan gum-5 wt\% GPTMS composite material, (b) Ni(II) ion-accumulated, (c) Y(III) ion-accumulated, and (d) Mg(II) ion-accumulated composite films at $2500-4000 \mathrm{~cm}^{-1}$. The scale bar in Figure 8 indicates the transmittance of $20 \%$. The concentration of the metal ions was 2000 ppm.

\subsection{Accumulative Mechanism of Metal Ions by the Composite Film}

In the accumulative experiment, the binding affinity of the metal ions to the gellan gum-GPTMS composite material could classify groups A-C. The metal ions in group A interacted the strongest with the composite film and the order of the binding affinity was group $\mathrm{C}<$ group $\mathrm{B}<$ group $\mathrm{A}$. In addition, the binding affinity of each metal ion was $\mathrm{Mg}$ (II) $<\mathrm{Al}(\mathrm{III}), \mathrm{Sc}$ (III) $<<\mathrm{Ca}$ (II), Y(III), $\mathrm{Cu}$ (II), $\mathrm{Zn}$ (II), $\mathrm{La}$ (III) $<\mathrm{In}(\mathrm{III})<<\mathrm{Ni}(\mathrm{II})$. These results suggested that the gellan gum-GPTMS composite film more strongly interacted with the heavy and the rare-earth metal ions than the light metal ions. We evaluated the accumulative effect of the metal ions based on the hydrated ion radius. For the divalent metal ions, the order of the hydrated ion radius size is $\mathrm{Ni}(\mathrm{II})<\mathrm{Cu}(\mathrm{II}), \mathrm{Ca}(\mathrm{II}), \mathrm{Zn}(\mathrm{II})<\mathrm{Mg}$ (II) $[29,30]$. This order was the reverse of the accumulation order of the metal ions and the metal ions with the smaller hydrated ion radius were more accumulated. According to the IR 
measurements, the gellan gum-GPTMS composite material has formed a dense structure by the encapsulation of the gellan gum into the three-dimensional network of the siloxane and the formation of covalent bonding between the hydroxyl groups in the gellan gum and the epoxy groups in GPTMS. The hydrated metal ions with the large hydrated ion radius cannot penetrate into the gellan gum-GPTMS composite material. As a result, the gellan gum-GPTMS composite film effectively accumulated the $\mathrm{Ni}$ (II) ions which have the smallest hydrated ion radius of these metal ions. These results suggested that the gellan gum-GPTMS composite film can effectively accumulate divalent metal ions, which possess a small, hydrated ion radius.

In the trivalent metal ions, the binding affinity partially coincided with the order of the hydrated ion radius size. The order of the hydrated ion radius size is $\mathrm{In}(\mathrm{III})<\mathrm{Sc}$ (III) $<$ $\mathrm{Y}(\mathrm{III})<\mathrm{La}(\mathrm{III})<\mathrm{Al}(\mathrm{III})$ [29,31-33]. The Al(III) ion, which possesses the largest hydrated ion radius of these metal ions, showed the smallest accumulated amount of these trivalent ions. The In(III) ions, which possess the smallest hydrated ion radius of these metal ions, showed the highest accumulated amount. This is due to the fact that the metal ion with the small hydrated ion radius is easier to penetrate into the network of the gellan gum-GPTMS composite material than metal ions with a large hydrated ion radius. In contrast, the $\mathrm{La}$ (III) and Y(III) ions with the large hydrated ion radius showed highly accumulated amounts. This is due to the coordination number. Generally, the La(III) and Y(III) ions possess various coordination numbers [34]. Since metal ions with various coordination numbers form various coordination structures, the composite material effectively accumulated the $\mathrm{La}$ (III) and Y(III) ions. These results suggested that the accumulation of trivalent metal ions by the gellan gum-GPTMS composite film was related to the size of the hydrated ion radius and the coordination number.

\section{Conclusions}

We prepared a water-insoluble gellan gum-GPTMS composite film by mixing gellan gum and a silane coupling reagent, GPTMS. The gellan gum was water-stabilized by the addition of $5 \mathrm{wt} \%$ GPTMS. In addition, the gellan gum-GPTMS composite film showed a thermal stability and mechanical strength. This is due to the formation of a threedimensional network. Furthermore, these composite films could accumulate metal ions from a metal ion-containing aqueous solution. The binding affinity was $\mathrm{Mg}(\mathrm{II})<\mathrm{Al}(\mathrm{III})$, $\mathrm{Sc}(\mathrm{III})<<\mathrm{Ca}(\mathrm{II}), \mathrm{Y}(\mathrm{III}), \mathrm{Cu}(\mathrm{II}), \mathrm{Zn}(\mathrm{II}), \mathrm{La}(\mathrm{III})<\mathrm{In}(\mathrm{III})<<\mathrm{Ni}(\mathrm{II})$. Based on IR measurements, although the accumulation of heavy and rare-earth metal ions occurred at both the $-\mathrm{COO}^{-}$ group and the $-\mathrm{OH}$ group in the gellan gum, the accumulation of light metal ions occurred only at the $-\mathrm{OH}$ group. The gellan gum-GPTMS composite film may have potential use in environmental, biomedical, and engineering applications.

Author Contributions: Conceptualization, M.Y.; methodology, M.Y.; software, M.Y. and Y.K.; validation, M.Y. and Y.K.; formal analysis, M.Y. and Y.K.; investigation, M.Y. and Y.K.; resources, M.Y.; data curation, M.Y.; writing—original draft preparation, M.Y.; writing—review and editing, M.Y.; visualization, M.Y.; supervision, M.Y.; project administration, M.Y.; funding acquisition, M.Y. All authors have read and agreed to the published version of the manuscript.

Funding: This research was funded by JSPS KAKENHI Grant Number JP19K12408, JP19K22298.

Data Availability Statement: All data generated or analyzed during this study are included in this published article.

Acknowledgments: This work was supported by JSPS KAKENHI Grant Number JP19K12408, JP19K22298.

Conflicts of Interest: The authors declare no conflict of interest. 


\section{References}

1. Bajaj, I.B.; Survase, S.A.; Saudagar, P.S.; Singhal, R.S. Gellan gum: Fermentative production, downstream processing and applications. Food Technol. Biotechnol. 2007, 45, 341-354.

2. O'Neill, M.A.; Selvendran, R.R.; Morris, V.J. Structure of the acidic extracellular gelling polysaccharide produced by Pseudomonas elodea. Carbohydr. Res. 1983, 124, 123-133. [CrossRef]

3. Hadeler, B.; Scholz, S.; Reski, R. Gelrite and agar differently influence cytokinin-sensitivity of a moss. J. Plant Physiol. 1995, 146, 369-371. [CrossRef]

4. Morris, E.R.; Nishinari, K.; Rinaudo, M. Gelation of gellan-A review. Food Hydrocoll. 2012, 28, 373-411. [CrossRef]

5. Osmałek, T.; Froelich, A.; Tasarek, S. Application of gellan gum in pharmacy and medicine. Int. J. Pharm. 2014, 466, 328-340. [CrossRef]

6. Nadzir, M.M.; Nurhayati, R.W.; Idris, F.N.; Nguyen, M.H. Biomedical applications of bacterial exopolysaccharides: A review. Polymers 2021, 13, 530. [CrossRef]

7. Rudko, M.; Urbaniak, T.; Musiał, W. Recent developments in ion-sensitive systems for pharmaceutical applications. Polymers 2021, 13, 1641. [CrossRef]

8. Kanesaka, S.; Watanabe, T.; Matsukawa, S. Binding effect of $\mathrm{Cu}^{2+}$ as a trigger on the sol-to-gel and coil-to-helix transition processes of polysaccharide, gellan gum. Biomacromolecules 2004, 5, 863-868. [CrossRef]

9. Ahmad, S.; Ahmad, M.; Manzoor, K.; Purwar, R.; Ikram, S. A review on latest innovations in natural gums based hydrogels: Preparations \& applications. Int. J. Biol. Macromol. 2019, 136, 870-890.

10. Erigoni, A.; Diaz, U. Porous silica-based organic-inorganic hybrid catalysts: A review. Catalysts 2021, 11, 79. [CrossRef]

11. Samiey, B.; Cheng, C.H.; Wu, J. Organic-inorganic hybrid polymers as adsorbents for removal of heavy metal ions from solutions: A review. Materials 2014, 7, 673-726. [CrossRef]

12. Sanchez, C.; Julián, B.; Belleville, P.; Popall, M. Applications of hybrid organic-inorganic nanocomposites. J. Mater. Chem. 2005, 15, 3559-3592. [CrossRef]

13. Pandey, S.; Mishra, S.B. Sol-gel derived organic-inorganic hybrid materials: Synthesis, characterizations and applications. J. Sol-Gel Sci. Technol. 2011, 59, 73-94. [CrossRef]

14. Plueddemann, E.P. Silane Coupling Agents, 2nd ed.; Plenum Press: New York, NY, USA, 1991.

15. Arakaki, A.; Shimizu, K.; Oda, M.; Sakamoto, T.; Nishimura, T.; Kato, T. Biomineralization-inspired synthesis of functional organic/inorganic hybrid materials: Organic molecular control of self-organization of hybrids. Org. Biomol. Chem. 2015, 13, 974-989. [CrossRef]

16. Yamada, M.; Aono, H. DNA-inorganic hybrid material as selective absorbent for harmful compounds. Polymer 2008, 49, 4658-4665. [CrossRef]

17. Monton, M.R.N.; Forsberg, E.M.; Brennan, J.D. Tailoring sol-gel-derived silica materials for optical biosensing. Chem. Mater. 2012, 24, 796-811. [CrossRef]

18. Nunes, S.C.; Bermudez, V.Z.; Silva, M.M.; Smith, M.J.; Morales, E.; Carlos, L.D.; Ferreira, R.A.S.; Rocha, J. Sol-gel derived $\mathrm{Li}^{+}$-doped poly( $\varepsilon$-caprolactone)/siloxane biohybrid electrolytes. J. Solid State Electrochem. 2006, 10, 203-210. [CrossRef]

19. Yamada, M.; Ogino, T. Anhydrous proton conductor consisting of pectin-inorganic composite material. J. Appl. Polym. Sci. 2015, 132, 42433-42439. [CrossRef]

20. Coradin, T.; Livage, J. Aqueous silicates in biological sol-gel applications: New perspectives for old precursors. Acc. Chem. Res. 2007, 40, 819-826. [CrossRef]

21. Yamada, M.; Abe, K. Selective accumulation of rare earth metal and heavy metal ions by DNA-inorganic hybrid material. Polym. J. 2014, 46, 366-371. [CrossRef]

22. Unnikrishnan, K.P.; Thachil, E.T. Toughening of epoxy resins. Des. Monomers Polym. 2006, 9, 129-152. [CrossRef]

23. Silverstein, R.M.; Webster, F.X. Spectrometric Identification of Organic Compounds; John Wiley \& Sons: New York, NY, USA, 1998.

24. Shi, L.; Gunasekaran, S. Preparation of pectin-ZnO nanocomposite. Nanoscale Res. Lett. 2008, 3, 491-495. [CrossRef] [PubMed]

25. Theophanides, T. Infrared Spectroscopy_Materials Science, Engineering and Technology; IntechOpen: London, UK, 2012.

26. Ma, S.; Liu, W.; Wei, Z.; Li, H. Mechanical and thermal properties and morphology of epoxy resins modified by a silicon compound. J. Macromol. Sci. A 2010, 47, 1084-1090. [CrossRef]

27. Yamada, M.; Shiiba, S. Preparation of pectin-inorganic composite material as accumulative material of metal ions. J. Appl. Polym. Sci. 2015, 132, 42056-42063. [CrossRef]

28. Lázaro, N.; Sevilla, A.L.; Morales, S.; Marqués, A.M. Heavy metal biosorption by gellan gum gel beads. Water Res. 2003, 37, 2118-2126. [CrossRef]

29. Tansel, B. Significance of thermodynamic and physical characteristics on permeation of ions during membrane separation: Hydrated radius, hydration free energy and viscous effects. Sep. Purif. Technol. 2012, 86, 119-126. [CrossRef]

30. Cheng, W.; Liu, C.; Tong, T.; Epsztein, R.; Sun, M.; Verduzco, R.; Ma, J.; Elimelech, M. Selective removal of divalent cations by polyelectrolyte multilayer nanofiltration membrane: Role of polyelectrolyte charge, ion size, and ionic strength. J. Membr. Sci. 2018, 559, 98-106. [CrossRef]

31. Rudolph, W.W.; Irmer, G. On the hydration of the rare earth ions in aqueous solution. J. Solut. Chem. 2020, 49, 316-331. [CrossRef]

32. Lindqvist-Reis, P.; Lamble, K.; Pattanaik, S.; Persson, I.; Sandström, M. Hydration of the yttrium(III) ion in aqueous solution. An X-ray diffraction and XAFS structural study. J. Phys. Chem. B 2000, 104, 402-408. [CrossRef] 
33. Lindqvist-Reis, P.; Persson, I.; Sandström, M. The hydration of the scandium(III) ion in aqueous solution and crystalline hydrates studied by XAFS spectroscopy, large-angle X-ray scattering and crystallography. Dalton Trans. 2006, 3868-3878. [CrossRef]

34. Cotton, F.A.; Wilkinson, G.; Gaus, P.L. Basic Inorganic Chemistry; John Wiley \& Sons: New York, NY, USA, 1991. 